\title{
POLÍTICAS PÚBLICAS E O DIREITO A CIDADE POR MEIO DA PARTICIPAÇÃO E DO CONTROLE DA JUSTIÇA SOCIAL
}

\author{
Rosana Gildo Vieira ${ }^{1}$
}

Luis Gabriel Rodrigues Souza ${ }^{2}$

\author{
Rosimara Carvalho Peixoto ${ }^{3}$
}

\begin{abstract}
RESUMO
A visão geral sobre o orçamento municipal deve ser implementado através de uma gestão direta para alcançar uma verdadeira justiça social. Entidades (União, estado e municípios), após a Constituição Federal de 1988, eles ganharam mais recursos e autonomia Federal, e os cidadãos, com base no estado democrático de direito, indiretamente adquiriram o direito de participar e ser ouvido pelo chefe do poder dessas entidades. Então, mesmo sendo uma tarefa difícil, o poder de decisão com a população deve sempre ser considerado em qualquer esfera do poder.
\end{abstract}

PALAVRAS-CHAVE: Orçamento. Política e Direitos Fundamentais. Gestão Participativa.

\section{PUBLIC POLICY AND THE RIGHT TO THE CITY THROUGH THE PARTICIPATION AND CONTROL OF SOCIAL JUSTICE}

\section{SUMMARY}

Overview of the municipal budget shouldnt be Implemented through the direct management of real social justice achievement. Entities such as The European Union; state and Municipalities, after the Federal Constitution of 1988, won more federal resources and autonomy. Then the citizens, on the basis of the democratic state of law, indirectly acquired the right to participate and be heard by the head of power of these entities. So, even though it's a difficult task; the capacity of decision making, with the population, shouldn't always be considered in every sphere of power

Keywords: Budget, policy and fundamental rights. Participatory Management.

\footnotetext{
${ }^{1}$ Graduada em Direito pela UNIVERSO, pós-graduada em Direito pela Universo, Gestora da E M Jose Manna Junior, Presidente do Conselho Municipal de Educacão

${ }^{2}$ Mestre em Ensino da Saúde e do Ambiente (UNIPLI), Prof. da Rede Municipal de São Gonçalo e da Rede Estadual do RJ

${ }^{3}$ Pós-graduada em Gestão da Educação Pública pela UFJF, Professor Inspetor Escolar da

SEEDUC/RJ, Professor da Rede Municipal do RJ.maracp@ymail.com
} 


\title{
POLÍTICAS PÚBLICAS Y EL DERECHO A LA CIUDAD A TRAVÉS DE LA PARTICIPACIÓN Y EL CONTROL DE LA JUSTICIA SOCIAL
}

\begin{abstract}
RESUMEN
El presupuesto municipal debe ser implementado a través de una gestión directa con el fin de obtener una justicia social verdadera. Los entes (Unión, estado y municipios), después de la Constitución Federal de 1988, ganaron autonomía federativa y más recursos, y los ciudadanos, sobre la base del Estado Democrático de Derecho, adquirieron indirectamente el derecho a participar y ser escuchados por el jefe del poder de estos entes. Así, incluso siendo una tarea difícil, el poder de decisión con la población debe ser siempre considerado en cualquier esfera de poder.
\end{abstract}

Palabras clave: presupuesto, política, derechos fundamentales, participativa.

\section{INTRODUÇÃO}

O Rio de Janeiro, desde a década de 80 , vem passando por várias mudanças, atingindo os mais diferenciados setores do eixo econômico, social, cultural e político; como exemplos, o surgimento de ONG, Entidades Representativas das diferentes Classes Trabalhadores-Sindicatos, de vagas para os cargos políticos na esfera municipal, e todas essas categorias trazem a tona e ao conhecimento da sociedade carioca, os inúmeros problemas enfrentados pelo município, tais como, por exemplo, transporte precário, falta de saneamento, médicos nas UPAS, (...).

Esse fenômeno informativo causou um aumento na preocupação do cidadão, que cumpre com suas obrigações tributárias e fiscais, no sentido de começarem a questionar se realmente está ocorrendo uma gestão pública municipal cidadã, ou seja, aquela por meio e uso do retorno dos tributos arrecadados para o município em ações de benefícios à população.

O Orçamento Participativo, segundo Pires (2001), representa "uma modalidade de participação popular que teve início e vem se consolidando num 


\section{Revista Nacional de}

Gerenciamento de Cidades

contexto específico do desenvolvimento socioeconômico e da vida política brasileira".(p13)

Para o autor o cidadão deixa de ser um simples coadjuvante para ser protagonista ativo da gestão pública.

Nesse contexto, o orçamento participativo é um importante instrumento de complementação da democracia representativa, pois permite que o cidadão debata e defina os destinos de uma cidade. Nele, a população decide as prioridades de investimentos em obras e serviços a serem realizados a cada ano, com os recursos do orçamento da prefeitura. Além disso, ele estimula o exercício da cidadania, o compromisso da população com o bem público e a co-responsabilização entre governo e sociedade sobre a gestão da cidade.

Ao longo do artigo, é apresentado o processo de implantação do orçamento governamental de forma participativa e os seus principais pontos, propondo um modelo estrutural de planejamento de curto prazo para os municípios.

\section{DESENVOLVIMENTO}

Nesse contexto, o processo de planejamento, de acordo com a Constituição de 1988, apresenta três peças importantes, que são: o plano plurianual (PPA), a lei de diretrizes orçamentárias (LDO); e a lei orçamentária anual (LOA). Neste momento, houve um reforço da concepção que associa o planejamento ao orçamento como componentes de um único sistema, tornando obrigatória a elaboração do Plano Plurianual.

A lei complementar $101 / 00$ foi criada para controlar os gastos do setor público, fiscalizando e normatizando-os. Além da sua função primordial - controlar os gastos públicos - a LRF abriu espaço para o planejamento, reforçando determinados pontos que a Constituição Federal de 88 normatizava, 


\section{Revista Nacional de}

Gerenciamento de Cidades

primordialmente no que se refere à vinculação dos instrumentos de planejamento (PPA, LDO e LOA), quando ressalta em seu art. $5^{\circ}$, que: "o projeto de lei orçamentária anual, elaborado de forma compatível com o plano plurianual, com a lei de diretrizes orçamentárias (...)"

O orçamento participativo é um instrumento que serve para alocar os recursos públicos de forma eficiente e eficaz. Recursos (receitas) que advêm primordialmente do poder do governo de tributar, devendo, pois, reverter tais recursos em benefícios coletivos (gasto público), sendo estes benefícios a materialização das demandas levantadas mediante as diferentes opiniões, interesses e desejos da comunidade.

Waldemir Pires (2000) em uma das suas inúmeras críticas ao desenvolvimento do controle do Orçamento pelo Estado, costuma ressaltar que: "a importância de controlar os gastos públicos costuma ser percebida somente depois do ponto crítico em que seu volume já ameaça a saúde da economia e/ou o bolso dos contribuintes." (p34)

Dessa forma o orçamento vem, gradativamente, assumindo dois papéis: o de instrumento e expressão da democracia, uma vez que a lei orçamentária está definida nos marcos do chamado Estado de Direito.

Vale salientar, que a metodologia do orçamento participativo permite que a sociedade participe, em um ou mais desses momentos do processo, de forma mais atuante e democrática. Porém, o que vem prevalecendo na maioria dos processos municipais é a participação social de forma indireta no momento da elaboração.

\section{PARTICIPAÇÃO E DO CONTROLE DA JUSTIÇA SOCIAL}

Esse artigo defende que é preciso uma gestão em que a população comece a opinar, a levantar e indicar necessidades, tudo em conjunto com o gestor público, porém de forma direta. 
É importante ressaltar que a participação do cidadão no Orçamento por meio de Plenárias Escolares permitirá a discussão de forma horizontal e direta das questões da coisa pública local, fomentando a cooperação de participantes que são encontrados na comunidade escolar e que estão inseridos em algumas dessas categorias, (igrejas, sindicatos, associações de bairro, cidadão inserido ou não em algum movimento), gerando a confiança social e permitindo solucionar dilemas de ação coletiva.

Conforme Pires (2001), “a metodologia dialética é uma das formas de garantir que o processo de implantação do orçamento participativo obtenha êxito", (p108).

Para Waldemir Pires, o município deveria ser a parte mais forte da federação, mas, ao contrário do esperado, hoje, o poder político encontra-se centrado nas esferas mais altas da administração pública.

\subsection{Modelo estrutural de planejamento de curto prazo para os municípios.}

a) Plenárias escolares: O caminho mais curto é começar a Realizar as plenárias nas escolas públicas com pais e alunos; (as escolas estão inseridas dentro de comunidades/bairros, onde cada um traria as necessidades de sua localidade;

b) Plenárias bairro: Ao final das plenárias escolares seria montado um relatório em que as três políticas públicas mais citadas e referendadas pela população daquele bairro seriam aquelas que comporia o Projeto Participativo.

c) Plenária área/zona: Os bairros são divididos por zona, exemplo (leste, sul, norte (...), nesse contexto, cada relatório de um bairro/zona com suas opções das três políticas públicas seriam analisadas em conjunto com as 


\section{Revista Nacional de \\ Gerenciamento de Cidades}

dos outros bairros na mesma área/zona e novamente o relatório apresentaria as três políticas públicas mais citadas.

d) Plenárias regionais e sub-regionais, ocorreriam após a reunião das plenárias temáticas área/zona, neste momento tem um aprofundamento e detalhamento dos reais programas que cada Plenária área/zona tem interesse populacional;

e) Avaliação dos resultados das plenárias e alocação dos recursos, reivindicados pela população local.

f) Apresentar projetos interativos com o interesse do povo, visando melhorar à produção e a qualidade de vida da população, se por exemplo, os três pontos vencedores na Plenária Zonais fossem o interesse através de infraestrutura, educação e saúde.

g) Encaminhar o projeto ao Prefeito ou Sub-Prefeito e este um Projeto de lei ao legislativo, o qual foi elaborado com o auxilio da população;

Neste caso, teríamos uma gestão onde governo e população, estariam convergindo a curto prazo para proporcionar um desenvolvimento econômico, social e cultural das referidas áreas/zonas populacionais. Uma vez que, as necessidades de cada região seriam elencadas, em termos de assistência aos interesses da comunidade, além de expor a situação de uma melhor infraestrutura de cada região.

Quando o orçamento participativo é posto em prática, tem-se uma política mais democrática e de acordo com as prioridades da região.

\section{CONCLUSÃO}


O orçamento público elaborado de forma conjunta entre o chefe do poder executivo municipal e a população tem ênfase na justiça social, onde o primeiro abre o espaço que antes pertencia a ele, para ouvir e levantar as prioridades, por meio da opinião do povo, e consequentemente elaborando projetos de prioridades dessa região. É inconcebível que muitos municípios brasileiros, como o do Rio de Janeiro, estejam fazendo uma Gestão indireta, aplicando uma forma de intercambio governo - sem a população.

O processo de orçamento participativo direto, leva em consideração este fato, por isso propomos neste artigo a implantação desta metodologia em área municipal, onde a carência e o descaso são frequentes. A aplicação deste tipo de processo tende a gerar um desenvolvimento local, haja vista serem debatidos os problemas e dificuldades pelos quais a população vem passando.

O tema da participação popular não é inédito na história do Brasil, mas, adquiriu um novo status na agenda política nacional, advindo das múltiplas transformações estruturais que vêm ocorrendo nas últimas décadas, quando o município passou a ser predominantemente urbano e industrial.

Nesse contexto de transformações estruturais, a redemocratização consagrada pela Constituição de 1988 determinou maior autonomia e mais recursos para os municípios, revalorizando o poder local - e a população urbana precisa ser ouvida, nos seus direitos básicos da cidadania, pressionando o Estado e o sistema político nascente a dar respostas para suas reivindicações pelo direito à cidade.

A importância de intervenção popular no orçamento público deriva exatamente do caráter nuclear que este possui como principal instrumento de gestão do Estado moderno. Todavia, trata-se de uma tarefa difícil, pois prevê o compartilhamento do poder de decisão com a população, seja por parte do corpo técnico-burocrático - que, em geral, detém o monopólio do saber técnico, das 
